\title{
Development of boutique denim clothing by the "upcycling" method
}

\author{
Magdalena Pavlova ${ }^{1, *}$ \\ ${ }^{1}$ Technical University of Sofia, Department of Textiles, 1000 Sofia, Bulgaria
}

\begin{abstract}
In the present article have been developed denim models for women's figures with deviations from the conditionally nominal sizes, using the method of re-creative use - upcycling, in pursuit of motivation to reduce the textile waste from the sewing industry. A combination of three approaches is used: a concept for a boutique vision when creating the design of the models, as an attraction for each user; upcycling as an idea for reusing sewing products; moulage method in the development of the construction of clothing, based on a classic basic construction. To confirm the results, physical samples of the products were made. The research and creative activity is aimed towards realization of a design and constructiontechnological concept of denim clothing, which is the most common clothing used by absolutely all age groups, from babies to centenarians and is present in both the prêt à porter and haute couture. This makes the production of denim products, one of the most voluminous and polluting in the textile industry.
\end{abstract}

\section{Introduction}

Overproduction and the rapid development of the industry worldwide are causing catastrophic damage to the environment and the planet. Various world organizations are developing new methods of clean production leaded by the motto "Save the planet". The fashion industry is the second most polluting industry after the oil industry, worldwide. Therefore, the fashion designers empathic to protecting the environment for future generations should engage in solving these problems. For this purpose, they create bio or eco fashion, use recycled raw materials and reused textiles, create "upcycling" clothing, etc. Creative reuse has grown significantly in countries such as the United States, where in recent years the number of products labeled "upcycled" has increased by between $300 \%$ and $900 \%$ [1]. The proposed approach opens a market niche with the possibility of Internetbased small business and is aimed towards developing of an active attitude to global environmental problems, both for designers and clothing users.

In search of motivation to reduce the textile waste from the garment industry, denim models have been developed [2], using a combination of three approaches: a concept for a boutique vision of the design; upcycling as an idea for reusing sewing products; moulage method in the development of clothing design, based on a classic basic design for women's

\footnotetext{
*Corresponding author: : mpavlova@tu-sofia.bg
} 
figures with deviations from the conditionally nominal sizes [3]. Upcycling or creative reuse to increase the value of the original product by changing and / or adding a personal view to the design of an already manufactured and used product [1]. The upcycling resources are used for as long as possible. Maximum value is extracted out of them, afterwards they are recovered several times, unlike the model purchase - use - disposal as waste. Upcycling as a method of clothing transformation is one of the solutions for sustainable living.

According to the moulage method [4], [5], the patterns are obtained directly from the human body or from a mannequin torso, by applying pieces of fabric or paper on its surface, after which the contours of the individual details are outlined in accordance with the model. The final shaping is done during the cutting and sewing. Several tests and corrections are mandatory.

\section{Methods and Results}

\subsection{Development of models}

Using the above combination of methods, two models of women's clothing were designed - a skirt and a jacket. Sketches of the designed products are presented on Fig.1.
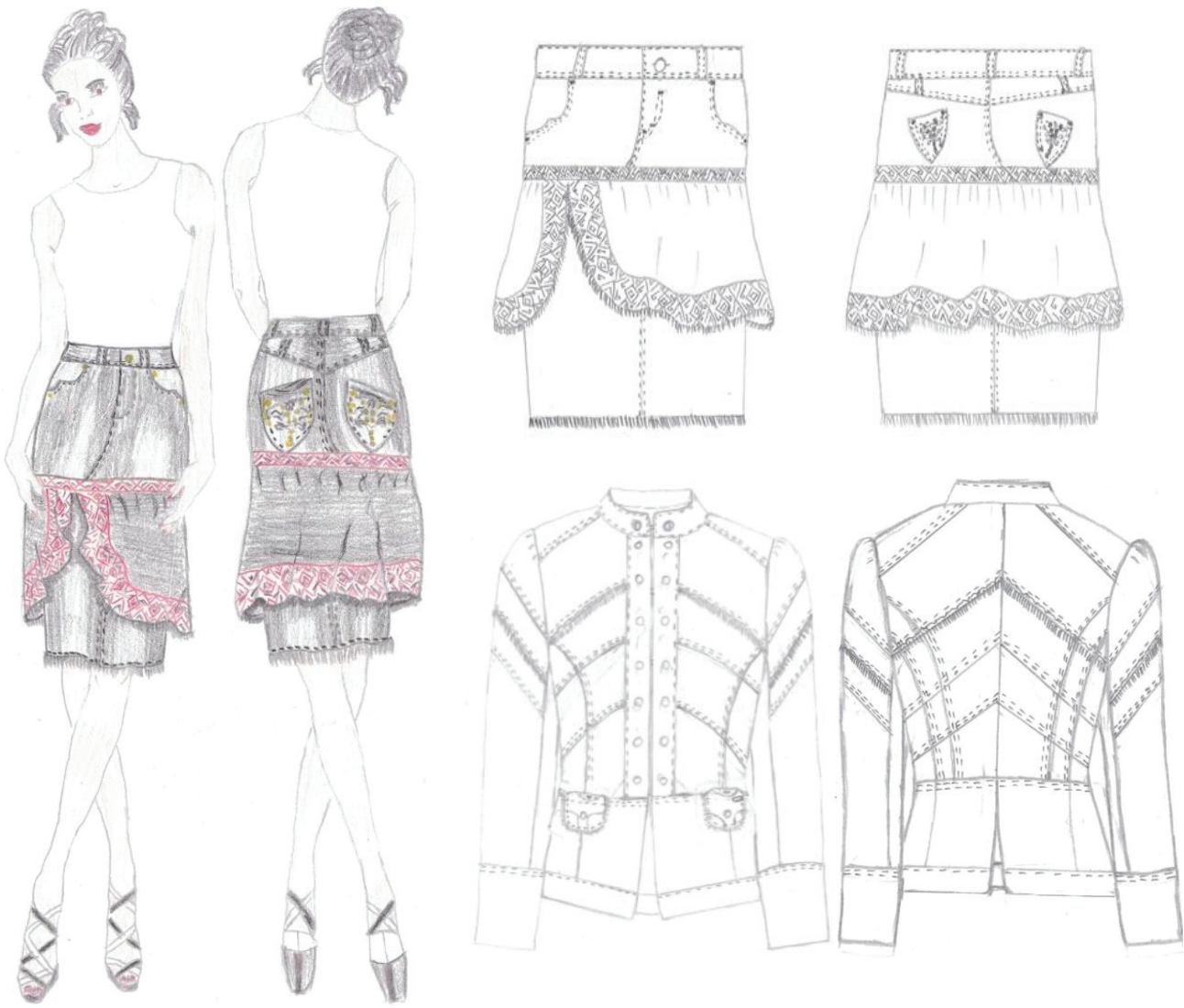

Fig. 1. Fashion sketches and technical drawings of the designed clothes

The first model is a women's skirt in a straight silhouette, with a length above the knee and a gathered element along the hips, covered by ethnic motifs. The fastening is central 
with a zipper and a button. The waist line is shaped with a belt and five loops. The side pockets are in shape. A triangular yoke is made on the back side. The pockets are externally attached with embroidered floral motifs.

The second model is a women's jacket in a semi-fitted silhouette with a length to the hip line, cut at the waist, with attached a long two seam sleeves. The front part is structurally divided in two along the waist line. The waist darts are transformed into princess seams. The design is completed by inclined decorative pieces in the front and back, which allow the use of multicoloured pieces. Along the waist in the front part there are 2 externally sewn pockets with a rounded shape. The fastening is by means of seven wire buttons, as the front parts touch frontally and are decorated with metal buttons. The back part has middle seam. A slit is made in the bottom part. The jacket has a collar with rounded edges. Three pairs of denim trousers in different colours were used for the production of the model - light blue, dark blue and black.

\subsection{Development of clothing construction}

The proposed combined approach, for creative reuse of clothing, is illustrated by creating two models of denim. Four jeans in different colours have been recycled. The designed clothing is made in two different ways, using the moulage method.

According to the first one the lady's skirt is formed directly on the human body, after the preliminary sketch, using direct cuts, outlining, fixing with pins and manual sewing. The finishing is done after undressing the products. A trial dressing is made to make further corrections, if necessary. The cycle is repeated until the desired result is achieved. Accepted corrections are fixed by stitches, according to the selected technology.

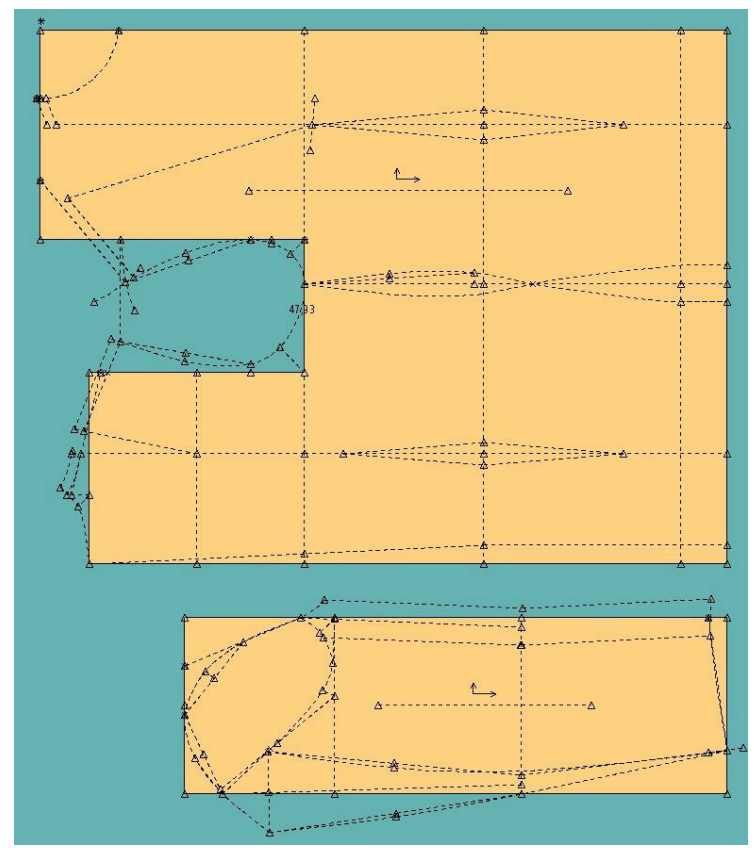

Fig. 2. Pattern making of the women's jacket - back, front and two seam sleeve

The women's jacket is developed by combining a base pattern according to a classical computational-analytical method and modeling as per the moulage method, following the "upcycling" principle. The product is modeled on the base construction, afterwards it is 
formed directly on the torso, according to the preliminary sketch. For the purpose has been developed a basic construction of a jacket in a semi-fitted silhouette. The initial construction is made out of textile waste. After several consecutive tests on a human body, the patterns are outlined and the details are tailored.The basic construction is developed for a female figure of standard size 48 (164/96/104). The horizontal structural sections are dimensioned with the following ease values along the main structural lines: along the chest line $8.0 \mathrm{~cm}$, along the waist line $8.0 \mathrm{~cm}$, along the hip line $7.0 \mathrm{~cm}$. The calculated front balance height is $5.2 \mathrm{~cm}$. The functional dependences for calculating the structural dimensions are according to [6]. The take away value in the middle back is $2.0 \mathrm{~cm}$. The additional length for gathering of the sleeve, obtained geometrically, is $3.7 \mathrm{~cm}$. The functionality [7] of the specialized clothing software AccuMark, version V10 of the company Gerber Technology, USA were used for the pattern making of the construction. An algorithm for automated construction has been developed. The output pieces - back, front and two seam sleeve are presented in Fig. 2. They are used as a initial stage for moulage.

Both products - skirt and jacket are obtained by transforming women's denim pants with an elastomeric component (Fig. 3a, 4a).

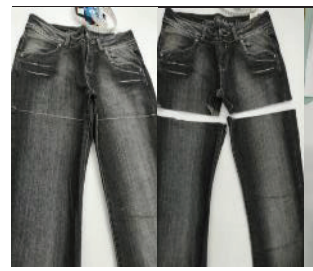

a

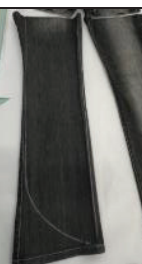

c

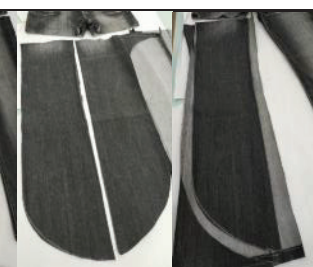

d

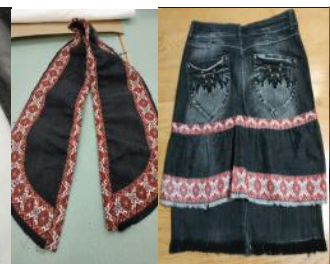

g

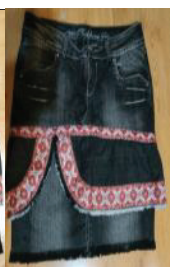

$\mathrm{h}$

Fig. 3. Photos of selected stages of the sequence for transforming the pants into a lady's skirt

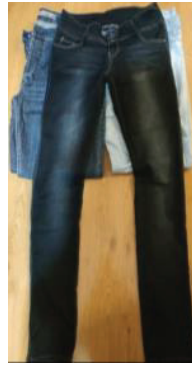

a

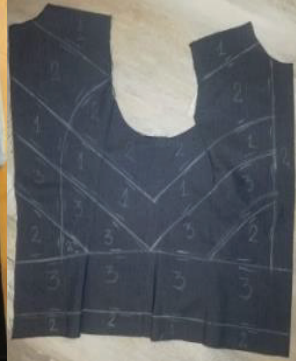

b

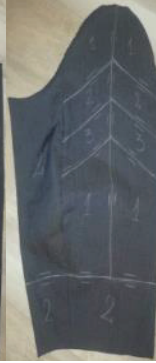

$\mathrm{C}$

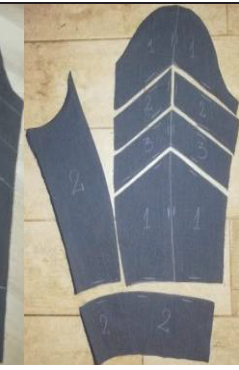

d

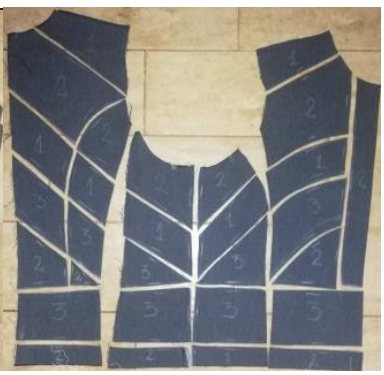

e

Fig. 4. Final adjustments, marking the details on the textile waste and cutting the patterns

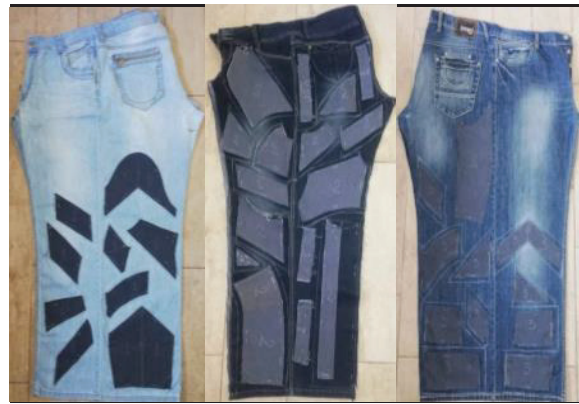

a

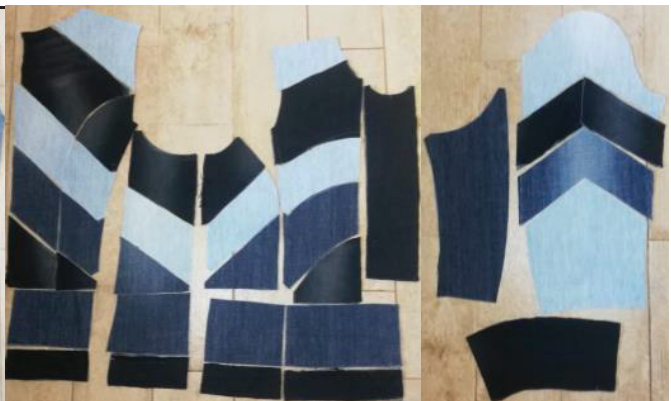

c

Fig. 5. Laying the production patterns on the jeans and cutting the details of the jacket 


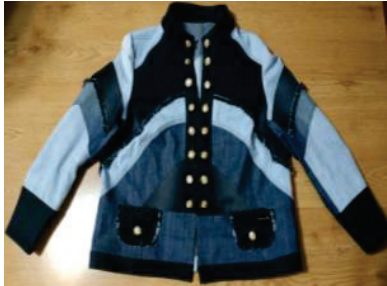

a

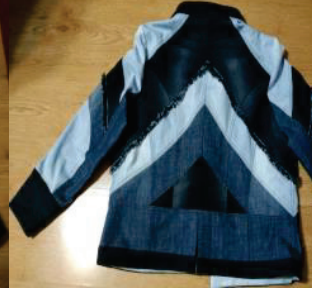

$\mathrm{b}$

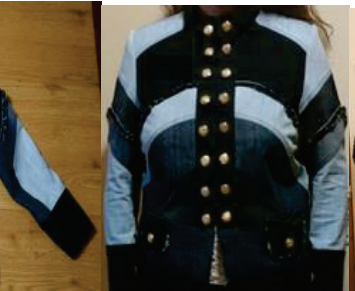

$\mathrm{c}$

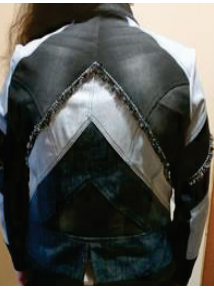

d

Fig. 6. Photos of the women's jacket, developed by the "upcycling" method

The models are presented with fashion sketches and technical drawings on Fig. 1. The stepwise transformation is illustrated by the photographic material on Fig. 3 a-h for the skirt and on Fig. 4a-e, Fig. 5 a-c. The final outlook of the women's jacket is presented face and back on Fig. 6 a - d. The sequence for transformation and production of the lady's skirt and lady's jacket is presented in details in Table 1 and Table 2 .

Table 1. Technological sequence map for transforming and manufacture a lady's skirt

\begin{tabular}{|c|c|c|c|c|}
\hline № & Name of the operation & Symbol & Stitch type & Comments \\
\hline 1 & 2 & 3 & 4 & 5 \\
\hline 1 & Outlining and cutting the details &,$x$ & Handwork & \\
\hline 2 & Overedge the band & 0 & 504 & \\
\hline 3 & Sew the parts for front bottom, back and band & of tho & $2 \times 301$ & With bar-tack \\
\hline 4 & $\begin{array}{l}\text { Sew the front middle seam in the area below } \\
\text { the zipper }\end{array}$ & 4 & 301 & $\begin{array}{l}\text { in the direction } \\
\text { of the right front }\end{array}$ \\
\hline 5 & Sew the back middle seam & 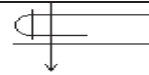 & 301 & $\begin{array}{l}\text { in the direction } \\
\text { of the right back }\end{array}$ \\
\hline 6 & Sew the middle of the gathered element & $=0$ & 401.504 & With bar-tack \\
\hline 7 & $\begin{array}{c}\text { Sew the decorative band at } 1 \mathrm{~cm} \text { fromt the } \\
\text { hem of the gathered element }\end{array}$ & & $2 \times 301$ & With bar-tack \\
\hline 8 & Reinforce the seam under the band & $\downarrow$ & 301 & Without bar-tack \\
\hline 9 & Set up the gathering of the gathered element & $\downarrow$ & 301 & \\
\hline 10 & $\begin{array}{c}\text { Sew the decorative band and the gathered } \\
\text { element }\end{array}$ & + & $2 \times 301$ & With bar-tack \\
\hline 11 & Outline and cut the the gathered element & 9 & Handwork & Handwork \\
\hline 12 & Sew the front and back bottom pieces & $=0$ & $401 \times 504$ & With bar-tack \\
\hline 13 & Sew the top and bottom part & $=0$ & $401 \times 504$ & With bar-tack \\
\hline 14 & Pressing the 13 & $\frac{1}{21}$ & Steam iron & \\
\hline 15 & Define the position of the gathered element & & & On the body \\
\hline 16 & Sew the gathered element & 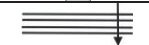 & 301 & With bar-tack \\
\hline 17 & Reinforce the seam $2 \mathrm{~cm}$ from the hem & $\mp$ & 301 & \\
\hline 18 & Unweave the hem of the gathered element & & Handwork & Handwork \\
\hline 19 & Threads and chalk cleaning & & Handwork & Handwork \\
\hline 20 & Final ironing & & Steam iron & \\
\hline
\end{tabular}

Table 2. Technological sequence map for transforming and manufacture a lady's jacket

\begin{tabular}{|c|c|c|c|c|}
\hline № & Name of the operation & Symbol & Stitch type & Comments \\
\hline $\mathbf{1}$ & $\mathbf{2}$ & $\mathbf{3}$ & $\mathbf{4}$ & $\mathbf{6}$ \\
\hline $\mathbf{0 0 . 0 0}$ & Cutting & & & \\
\hline $\mathbf{0 0 . 0 1}$ & Numbering & & Handwork & Handwork \\
\hline $\mathbf{0 0 . 0 2}$ & $\begin{array}{c}\text { Fuse the top and bottom collar, } \\
\text { plastron }\end{array}$ & $\perp$ & Steam iron & \\
\hline $\mathbf{0 1 . 0 0}$ & FRONT & & & \\
\hline
\end{tabular}




\begin{tabular}{|c|c|c|c|c|}
\hline 01.01 & Sew the component pieces & 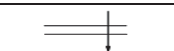 & 301 & With bar-tack \\
\hline 01.02 & Overedge the seam allowances & $=10$ & 504 & \\
\hline 01.03 & Pressing the 01.02 & $\stackrel{\perp}{\Phi}$ & Steam iron & \\
\hline 01.04 & $\begin{array}{l}\text { Reinforce the seam on the diagonal } \\
\text { seams }\end{array}$ & 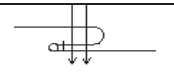 & 302 & \\
\hline 01.05 & Unweave the seam allowance & & Handwork & $1 \mathrm{~cm}$ \\
\hline 01.06 & Making a decorative seam & $+\frac{1}{=}$ & 213 & Put in a thread \\
\hline 01.07 & $\begin{array}{l}\text { Sew the front middle and the front } \\
\text { side part }\end{array}$ & $\rightleftharpoons$ & 301 & With bar-tack \\
\hline 01.08 & Overedge the seam allowances & +0 & 504 & \\
\hline 01.09 & Pressing the 01.08 & $\frac{\perp}{2}$ & Steam iron & \\
\hline 01.10 & Making a decorative seam & 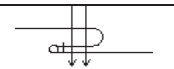 & 302 & \\
\hline 01.11 & Fold and press of the plastron & $\stackrel{\perp}{\longrightarrow}$ & Steam iron & \\
\hline 01.12 & Sew the front piece and the plastron & $\neq$ & 301 & With bar-tack \\
\hline 01.13 & Pressing the 01.12 & $\stackrel{\perp}{P}$ & Steam iron & \\
\hline 01.14 & Closing seam of the plastron & 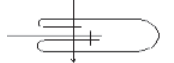 & 301 & Without bar-tack \\
\hline 01.15 & $\begin{array}{l}\text { Sew the bottom front middle and the } \\
\text { front side part }\end{array}$ & 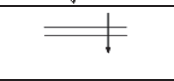 & 301 & With bar-tack \\
\hline 01.16 & Overedge the seam allowances & 10 & 504 & \\
\hline 01.17 & Pressing the 01.16 & $\stackrel{\perp}{21}$ & Steam iron & \\
\hline 01.18 & Sew the pieces of the hem band & 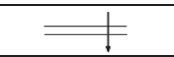 & 301 & Without bar-tack \\
\hline 01.19 & Pressing the 01.18 & $\frac{1}{x}$ & Steam iron & \\
\hline 01.20 & Sew the two bands & 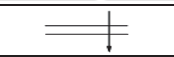 & 301 & With bar-tack \\
\hline 01.21 & Press with the edge & $D^{\frac{1}{2}}$ & Steam iron & $\begin{array}{c}\text { The edge towards } \\
\text { the inner band }\end{array}$ \\
\hline 01.22 & Attach the band with a top seam & 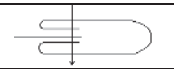 & 301 & \\
\hline 02.00 & BACK & & & \\
\hline 02.01 & Sew the component pieces & 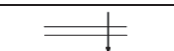 & 301 & Without bar-tack \\
\hline 02.02 & Overedge the seam allowances & 10 & 504 & \\
\hline 02.03 & Sew the back middle seam & 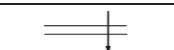 & 301 & With bar-tack \\
\hline 02.04 & Sew the middle and the side part & $=$ & 301 & With bar-tack \\
\hline 02.05 & Overedge the seam allowancesca & 10 & 504 & \\
\hline 02.06 & Making a decorative seam & $\mathrm{p}_{\mathrm{N}}$ & 302 & \\
\hline 02.07 & Unweave the seam allowance & & Handwork & $1 \mathrm{~cm}$ \\
\hline 02.08 & Making a decorative seam & $+\frac{1}{1}$ & 213 & Put in a thread \\
\hline 02.09 & $\begin{array}{l}\text { Sew the back middle and back side } \\
\text { part }\end{array}$ & 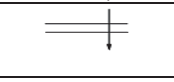 & 301 & With bar-tack \\
\hline 02.10 & Overedge the seam allowances & $=0$ & 504 & \\
\hline 02.11 & Pressing the 02.10 & $\stackrel{\perp}{11}$ & Steam iron & $\begin{array}{c}\text { Towards the back } \\
\text { middle }\end{array}$ \\
\hline 02.12 & $\begin{array}{l}\text { Make a decorative seam on the } \\
\text { assembly seams }\end{array}$ & $\mathrm{p}_{\mathrm{N}}$ & 302 & \\
\hline 02.13 & Overedge the seam allowances & $\theta$ & 504 & \\
\hline
\end{tabular}




\begin{tabular}{|c|c|c|c|c|}
\hline 02.14 & Sew the slit & 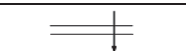 & 301 & With bar-tack \\
\hline 02.15 & Press with a edge & $P^{1}$ & Steam iron & \\
\hline 02.16 & Sew the pieces of the bands & 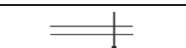 & 301 & Without bar-tack \\
\hline 02.17 & Assembly the bands & 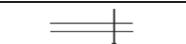 & 301 & With bar-tack \\
\hline 02.18 & Press with a edge & $\stackrel{1}{ \pm}$ & Steam iron & \\
\hline 02.19 & Close the band with a top seam & 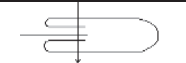 & 301 & \\
\hline 03.00 & COLLAR & & & \\
\hline 03.01 & Assembly the inner and upper collar & 要表 & 301 & With bar-tack \\
\hline 03.02 & Sew a reinforcing seam & 茟 & 301 & \\
\hline 03.03 & Cut the seam allowance & $8<$ & Handwork & Handwork \\
\hline 03.04 & Turn the collar to the face side & $\underset{\#}{\#}$ & Handwork & Handwork \\
\hline 03.05 & Pressing the 03.04 & ${ }^{\perp}$ & Steam iron & $\begin{array}{l}\text { The edge towards } \\
\text { the inner collar }\end{array}$ \\
\hline 04.00 & SLEEVES & & & \\
\hline 04.01 & Sew the component pieces & 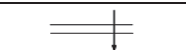 & 301 & Without bar-tack \\
\hline 04.02 & Overedge the seam allowances & 10 & 504 & \\
\hline 04.03 & Making a decorative seam & $\mathrm{p}_{4}$ & 302 & \\
\hline 04.04 & Sew the elbow seam & + & 301 & With bar-tack \\
\hline 04.05 & Overedge the seam allowances & 10 & 504 & \\
\hline 04.06 & $\begin{array}{l}\text { Lies on one side and press the ellbow } \\
\text { seam }\end{array}$ & $\stackrel{\perp}{2}$ & Steam iron & \\
\hline 04.07 & Sew the inner seam of the sleeve & $\Longrightarrow$ & 301 & With bar-tack \\
\hline 04.08 & Overedge the operation 04.07 & +0 & 504 & \\
\hline 04.09 & $\begin{array}{c}\text { Lies on one side and press the inner } \\
\text { seam }\end{array}$ & $\stackrel{1}{2}$ & Steam iron & \\
\hline 04.10 & Assembly the inner and upper cuff & 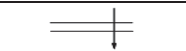 & 301 & With bar-tack \\
\hline 04.11 & $\begin{array}{l}\text { Turn the cuff to the face side and } \\
\text { press with a edge }\end{array}$ & $\stackrel{1}{P}$ & Steam iron & $\begin{array}{l}\text { towards the inner } \\
\text { cuff }\end{array}$ \\
\hline 04.12 & Sew the inner cuff and the sleeve & 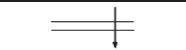 & 301 & With bar-tack \\
\hline 04.13 & Closing seam of the cuff & 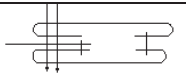 & 302 & With bar-tack \\
\hline 05.00 & ASSEMBLY & & & \\
\hline 05.01 & Sew the shoulders and the side seams & + & 301 & Without bar-tack \\
\hline 05.02 & Overedge the seam allowances & 10 & 504 & \\
\hline 05.03 & $\begin{array}{l}\text { Lies on one side and press the } \\
\text { assembly seams }\end{array}$ & $\stackrel{\perp}{\perp}$ & Steam iron & \\
\hline 05.04 & $\begin{array}{c}\text { Making a decorative seam of the } \\
\text { shoulders }\end{array}$ & $\mathrm{p}_{4}$ & 302 & With bar-tack \\
\hline 05.05 & $\begin{array}{l}\text { Sew the front bottom pieces and the } \\
\text { back }\end{array}$ & 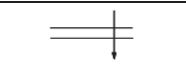 & 301 & Without bar-tack \\
\hline 05.06 & Overedge the seam allowances & $=10$ & 504 & \\
\hline 05.07 & $\begin{array}{l}\text { Lies on one side and press the } \\
\text { assembly seams }\end{array}$ & $\stackrel{1}{2}$ & Steam iron & \\
\hline
\end{tabular}




\begin{tabular}{|c|c|c|c|c|}
\hline 05.08 & Sew the top and bottom part & 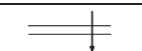 & 301 & Without bar-tack \\
\hline 05.09 & Overedge the seam allowances & $=10$ & 504 & \\
\hline 05.10 & $\begin{array}{c}\text { Lies on one side and press the } \\
\text { assembly seams }\end{array}$ & $\stackrel{\perp}{\perp}$ & Steam iron & \\
\hline 05.11 & Sew the front and the pocket & 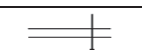 & 301 & decorative seam \\
\hline 05.12 & $\begin{array}{l}\text { Unweave the seam allowance of the } \\
\text { pocket }\end{array}$ & & Handwork & $1 \mathrm{~cm}$ \\
\hline 05.13 & Assembly the collar and the neck line & \begin{tabular}{l|l}
$\bar{E}$ \\
\end{tabular} & 301 & With bar-tack \\
\hline 05.14 & Pressing the 05.13 & $\frac{1}{1}$ & Steam iron & \\
\hline 05.15 & Assembly the sleeves and armhole & $\neq$ & 301 & With bar-tack \\
\hline 05.16 & Overedge the seam allowances & 10 & 504 & \\
\hline 05.17 & Press the armhole & $\stackrel{\perp}{21}$ & Steam iron & \\
\hline 06.00 & Finishing & & & \\
\hline 06.01 & Mark the place of the buttons & & Handwork & Handwork \\
\hline 06.02 & Sew the buttons & $::$ & Handwork & Handwork, $25 p$ \\
\hline 06.03 & Threads and chalk cleaning & & Handwork & Handwork \\
\hline 06.04 & Final ironing & & Steam iron & \\
\hline
\end{tabular}

\section{Conclusions}

The article proposes a creative method for reducing textile waste from the sewing industry. A women's skirt and a women's jacket of denim clothing has been created. A combination of three approaches is used: a concept for a boutique vision when creating the design of the models, as an attraction for each user; upcycling as an idea for reusing sewing products; moulage method in the development of the construction of clothing, based on a classic basic construction. The effect is also enhanced by the focus on denim products, whose production is one of the largest in the textile industry. To confirm the results, physical samples of the products were made.

The proposed approach opens a market niche with the possibility of Internet-based small business and is aimed towards developing of an active attitude to global environmental problems, both for designers and clothing users.

\section{References}

1. https://intercongreen.com/2010/02/17/recycling-vs-upcycling-what-is-the-difference/

2. Nencheva M., Anti-consumer approach to create denim clothes using the principle of upcycling and mulage, Diploma thesis, Sliven (2020)

3. Atanasova, R., D. Kasabova, Design of mass customized women's clothing, National Textile Conference 2014, Book of reports, ISBN: 978-954-91951-2-5, pp. 223-232, Sofia (2014)

4. https://www.universityoffashion.com/

5. Pavlova, M., R. Atanasova, Developing a creative method for reuse of clothing, E3S Web Conference, Vol. 207, https://doi.org/10.1051/e3sconf/202020703006, PEPM'2020, (2020)

6. Petrov, Hr., Apparel Pattern Making,TU-Sofia, Sofia (2009)

7. Without author, User's guide AccuMark Professional Edition V10.0, Gerber Technology Inc., a Business Unit of Gerber Scientific International (2015)

8. https://textilebeat.com/wp-content/uploads/2014/12/Global-apparel-fibre-consumptionvs-population-FINAL.jpg 